\title{
Baseline susceptibility of different European lepidopteran and coleopteran pests to Bt proteins expressed in Bt maize: a systematic review
}

Kai U. Priesnitz ${ }^{*}$, Anja Vaasen ${ }^{\dagger}$ and Achim Gathmann ${ }^{\dagger}$

\begin{abstract}
Background: Lepidopteran and coleopteran species are the most important pests in maize. They can be controlled using genetically modified (GM) crops expressing insecticidal Bacillus thuringiensis (Bt) proteins. The long-term success of this technology demands a pest resistance management. Important information for the successful management of resistance is the baseline susceptibility of the different target pests to the different $B t$ proteins. The data on baseline susceptibility should enable risk assessors and managers to assess whether a GM maize produces a Bt protein in a high-dose to specific target organisms and resistance has evolved during the commercial cultivation of this GM maize events.
\end{abstract}

Methods: Our systematic search followed an a priori protocol including the database platforms Web of Science, Scopus, CAB abstracts, Science Direct and JSTOR. We additionally conducted a Google scholar search. We collated all search results and screened all retrieved articles using predetermined inclusion criteria. We identified 30 studies, which fulfilled the criteria of including a relevant Bt protein, a relevant species, an appropriate endpoint, and fieldderived pest generations reared in the laboratory no longer than three generations. We then made a quality assessment to discover if the studies considered the dose response curves with confidence intervals, described the protein source, tested the protein concentration and the protein activity via positive controls, use more than ten larvae per concentration, more than two replications, and more than five protein concentrations. Since no quantitative synthesis was possible the synthesis of the results was done in a narrative form.

Results: Seventy percent of the studies fulfilled five or more criteria and $17 \%$ fulfilled four of the seven criteria. Six $B t$ proteins were tested on one or more of the four species Ostrinia nubilalis, Helicoverpa armigera, Sesamia nonagrioides, and Diabrotica virgifera virgifera. We extracted the baseline susceptibility for the given protein-species-combinations and the test method with the Bt protein applied either on the surface of the diet or incorporated. Although, the data displays a high heterogeneity and are thus hard to compare, they give an overview of the baseline susceptibility of lepidopteran/coleopteran pests to Bt proteins.

Conclusion: Our systematic review illustrates the heterogeneity of the data and indicates the necessity of standard protocols for testing susceptibility of insect pests, which provide comparable data. The cultivation of Bt crops, as with any other plant protection measure, is likely to result in resistance evolution in the target pests. Industry, policy makers, and research should combine knowledge to protect the benefits of this technology.

\footnotetext{
*Correspondence: kai.priesnitz@bvl.bund.de

${ }^{\dagger}$ Kai U. Priesnitz, Anja Vaasen and Achim Gathmann contributed equally

to this work

Department Genetic Engineering, Unit Coexistence

and GMO-Monitoring, Federal Office of Consumer Protection and Food

Safety (BVL), Mauerstr. 39-42, 10117 Berlin, Germany
} 
Keywords: European corn borer, Ostrinia nubilalis, Western corn rootworm, Diabrotica virgifera virgifera, Cry protein, Toxicity, Bacillus thuringiensis, Maize pests

\section{Background}

Lepidopteran and coleopteran species are the most important pests in maize. Several factors affect the effectiveness of control measures. The stem boring and root feeding life style of some pest species reduces exposure to insecticides, which creates difficulties to effectively control these species by spraying. Resistance evolution to conventional insecticides can cause ineffectiveness of treatments. Certain farming practices such as continuous or frequent maize cultivation and no tillage lead to higher pest pressure. In addition, there is a desire to reduce the environmental harm caused by insecticides.

An alternative approach to control these pests is the use of genetically modified (GM) crops expressing Bacillus thuringiensis derived insecticidal proteins (Bt proteins).

However, one concern in growing maize is the potential for resistance evolution against control measures, which is a well-known problem for more than 100 years [1]. This phenomenon occurs regularly where pest populations are exposed to uniform, strong and continuous selection pressure [1-3] and will evolve as a result of cultivating insect resistant GM plants. In consequence, $B t$ products might lose their effectiveness either as conventional spray applications or when expressed as transgenic traits in GM crops. Therefore, it is desirable that pest resistance management accompanies the cultivation of $B t$ crops to delay the evolution of resistance to B. thuringiensis products [4].

The regulatory risk assessment in the European Union (EU) considers impacts of the changes in management associated with the GM crop including the consequences of pest resistance evolution, and therefore also considers the efficacy of strategies by applicants delaying the expected resistance evolution. The most common strategy is the "high-dose/refuge" strategy (e.g. $[1,5]$ ), which includes monitoring and models to forecast the evolution of resistance [6].

The principles of the high-dose/refuge strategy used in these models are that (1) the $B t$ protein kills most of the susceptible pest population feeding on GM plants (highdose), (2) the frequency of resistance alleles is low in the pest population, (3) the inheritance of resistance is fully recessive, (4) rare resistant pests surviving on Bt crops mate with susceptible populations from nearby refuges of non- $B t$ host plants [5], and (5) fitness costs are associated with the evolution of resistance [7]. Therefore, all relevant data on the biology of the target pests, the characteristics of the modified plant and the GM trait are needed to create the model. In case not all requirements for the high-dose/refuge strategies are fulfilled, a modified strategy or additional measures might be needed. One of the most important sources of information to model the potential for resistance to evolve in a pest/crop system is the baseline susceptibility of the target organisms to $B t$ proteins.

Data on baseline susceptibility should enable risk assessors and managers to assess whether $B t$ maize events present a high-dose to specific target pests and whether resistance has evolved after commercial introduction of $B t$ maize events.

\section{Objective of the review}

In order to study the available information on baseline susceptible of certain pests, we formulated the following review question:

How susceptible are different lepidopteran/coleopteran maize pests to Bt proteins?

The research question has the following components:

$\mathrm{P}=$ Population: the populations considered are all lepidopteran or coleopteran pest species in maize, which are intended to be controlled by $B t$ maize in Europe. These include Ostrinia nubilalis, Sesamia nonagrioides, and Diabrotica virgifera virgifera, which are defined as the focal target species for GM Bt maize being cultivated or developed for cultivation in the EU and elsewhere. Additionally lepidopteran or coleopteran pest species should be considered, which might be of economic relevance in maize cultivation. The selection of considered species is based on an extended review initiated by the European Food Safety Authority (EFSA) [8].

$\mathrm{I} / \mathrm{E}=$ intervention/exposure: exposure to $B t$ proteins in the $B t$ crop.

$\mathrm{O}=$ outcome: baseline susceptibility data of lepidopteran and coleopteran pest species on different $B t$ proteins.

The goal of the systematic review (SR) was to collect as much data as possible on baseline susceptibility of different lepidopteran/coleopteran maize pests to $B t$ proteins expressed in $B t$ maize varieties, in order to have a broad data base on which to model and assess the potential for evolution of resistance of different crop- $B t$ protein-speciescombinations and to identify potential knowledge gaps.

\section{Methods}

This review was part of the EU funded project GRACE (GMO risk assessment and communication of evidence, http://www.grace-fp7.eu/) to collate available evidence 
on evolution of resistance to Bt crops relevant in Europe. The review team and the stakeholder group for this review were formed by project scientists and representatives of NGOs, authorities, industry and science. We published an a priori systematic review protocol [9] that describes our methods in detail and made no changes to methodology in our final systematic review. However, we present here a summary of our methods and give additional information about the details of the selection procedure for articles and the data they contained.

\section{Searches}

The aim of our search was to obtain unbiased and comprehensive information relevant to our review question. We collected data of different populations of lepidopteran or coleopteran pests following our published protocol [9]. We collated both published and unpublished data. We used different sources of information in order to maximize the coverage of the search. We conducted all searches in English. The searches were performed on the 4th of July, 2014.

\section{Search term}

As described in our protocol we developed a basic search term [9]: (lepidopter* OR butterf"* OR coleopter* OR beetl*) AND (toxi* OR cry* OR vip3* OR Bacillus thuringiensis* OR bt) AND (suscept" OR resist*). In advance, we chose fifteen relevant publications to test the search requirements. We found all publications using our search strings. We adapted the search term to the different search algorithms of the different databases respectively.

\section{Database sources}

We considered the following database sources:

Thomson Reuters (formerly ISI) Web of Science, New York, USA, http://apps.webofknowledge.com search string: (lepidopter* OR butterfl* OR coleopter* OR beetl*) AND (toxi* OR cry* OR vip3* OR Bacillus thuringiensis" OR bt) AND (suscept" OR resist")

[Basic search in: all databases, all topics, all years]

Scopus by Elsevier, Amsterdam, The Netherlands, http:// www.scopus.com/

search string: (lepidopter* OR butterfl* OR coleopter* OR beetl") AND (toxi* OR cry* OR vip3* OR Bacillus thuringiensis* OR bt) AND (suscept" OR resist*)

[Basic search in: all fields, all years]

$C A B$ abstracts, CABI, Wallingford, United Kingdom, http://www.cabdirect.org/

search string: (lepidopter* OR butterfl* OR coleopter* OR beetl*) AND (toxi* OR cry* OR vip3* OR Bacillus thuringiensis* OR bt) AND (suscept* OR resist*)
[Basic search]

JSTOR by Ithaka, USA, http://www.jstor.org/

searchstring: (((ab:(lepidopter* OR butterfl* OR coleopter* OR beetl*)) AND ab:(toxi* OR cry* OR vip3* OR Bacillus thuringiensis* OR bt)) AND ab:(suscept* OR resist")) AND la:(eng OR en)

[Advanced search, in abstracts, in English]

Google scholar (https://scholar.google.de/)

search string: (lepidopter* OR butterfl* OR coleopter* OR beetl*) AND (toxi* OR cry* OR vip3* OR Bacillus thuringiensis" OR bt) AND (suscept" OR resist")

Additionally to the listed data bases in the protocol we searched ScienceDirect by Elsevier, Amsterdam, The Netherlands, http://www.sciencedirect.com/

search string: (lepidopter* OR butterfl* OR coleopter* OR beet * $^{*}$ AND (toxi* OR cry* OR vip3* OR Bacillus thuringiensis* OR bt) AND (suscept* OR resist*)

[Advanced search]

Altogether, we contacted 17 recognized European experts in the area of resistance evolution in $B t$ crops via email to provide further unpublished information or missing data.

\section{Reference manager database}

We imported the results of each search into a separate library of Reference Manager [10]. We transferred the first fifty results of the Google Scholar search in a Reference manager file, also. Then we combined all references in a single library. We identified and deleted the duplicates.

\section{Article screening and study inclusion criteria}

The primary inclusion criteria for relevant studies were:

1. Pest species of maize with economic relevance or regionally economic relevance in Europe based on EFSA data base listing arthropods species in crop fields [8],

2. Toxicity tests with lepidopteran or/and coleopteran specific $B t$ proteins expressed in $B t$ maize

3. Toxicity tests with $B t$ proteins expressed in $B t$ maize, testing the endpoints $\mathrm{LC}_{50}$ (Lethal Concentration for $50 \%$ of test organisms), $\mathrm{EC}_{50}$ (Effective Concentration for $50 \%$ of the test organisms), or $\mathrm{MIC}_{50}$ (moult inhibitory concentration for $50 \%$ of the test organisms),

4. Laboratory studies using field collected test organisms that have been reared in the laboratory for not more than three generations.

We conducted the screening as described in the protocol. A Kappa analysis ensured that there was a high level of agreement between the two researchers applying the inclusion criteria. 


\section{Quality criteria}

For assessing the quality of the included publications, we considered the following criteria:

1. A full description of the protein source should be provided,

2. The bioactivity of the $B t$ protein should be verified with an experimental design including a positive control,

3. The tested concentration and integrity of the $B t$ protein in the diet of the test organisms should be confirmed by ELISA or Western Blot,

4. Ten or more larvae should be tested per concentration,

5. The experimental design should contain a minimum of two replications,

6. The experimental design should contain five or more different protein concentrations,

7. The dose response curves should be characterised by $\mathrm{LC}_{50} / \mathrm{EC}_{50} / \mathrm{MIC}_{50}$ and/or $\mathrm{LC}_{90} / \mathrm{EC}_{90} / \mathrm{MIC}_{90}$ with CIs of the different values.

\section{Data extraction strategy}

We collected data in 34 categories (Additional file 1: Table S1). We then extracted data of the categories "Species", "Bt protein", "number of tested populations", "minimum and maximum values of the $\mathrm{LC}_{50} / \mathrm{EC}_{50} / \mathrm{MIC}_{50}$ " into an Excel file.

\section{Results}

\section{Screening}

Before the specific screening, we removed the duplicates of our initial search (see Fig. 1). We screened 7943 articles on their title. Afterwards 1595 articles remained and we screened them at abstract level. The detailed screening process can be tracked within the supplemental information. We present the Excel files from our literature database after each screening step (Additional file 2: Table S2, Additional file 3: Table S3, Additional file 4: Table S4, Additional file 5: Table S5, Additional file 6: Table S6). A kappa coefficient of 0.81 proofed an almost perfect agreement of the two researchers.

\section{Study inclusion}

After screening the titles and the abstracts of the extracted articles, 212 published articles and four articles of grey literature remained. Checking the full text of these articles using the inclusion criteria as the standard, there were 28 articles that fulfilled none of these criteria, two articles were reviews and did not include original research data. We could not screen four articles in detail because it was not possible to receive a full text version. Consequently, we excluded these articles.
Approximately $40 \%$ assessed the preferred endpoint $\mathrm{LC}_{50}, \mathrm{EC}_{50}$, or $\mathrm{MIC}_{50}$. In the other articles endpoints such as mortality/survival or performed a selection breeding to gain resistant insects were assessed. In approximately $20 \%$ of the articles test populations reared in the laboratory for not more than three generations were used (the detailed results are described in Fig. 2; Additional file 7: Table S7).

Overall, 30 articles fulfilled all four criteria and therefore we assessed them further. These articles contained 32 different studies (two species were tested in two of the articles), and they observed four of the twelve species tested as economically or regional economically relevant pests in Europe [8]. These were the lepidopteran species Ostrinia nubilalis, Sesamia nonagrioides, Helicoverpa armigera, and the coleopteran species Diabrotica virgifera virgifera. Additionally we screened grey literature for their suitability using the inclusion criteria and identified three studies [9-11]. Since all relevant data from these studies were published in peer-reviewed journals and these publications were included in our review, we omitted the grey literature.

\section{Study quality assessment}

In the next step, we evaluated the quality of the surveys based on seven quality standards. Characterising the dose response curves by $\mathrm{LC}_{50}, \mathrm{EC}_{50}$, or $\mathrm{MIC}_{50}$ and/ or $\mathrm{LC}_{90}, \mathrm{EC}_{90}$, or $\mathrm{MIC}_{90}$ with CIs (confidence intervals) of the different values was done by $97 \%$ of the studies. The description of the source of the protein was given by $87 \%$ of the datasets. Another quality criterion was to test at least ten larvae per concentration, which was also performed in $87 \%$ of the datasets. A minimum of two replications was performed in approx. $77 \%$ of the investigations and $63 \%$ of the researchers used five or more different protein concentrations. In $57 \%$ of the studies the concentration and integrity was checked with an ELISA test or Western Blot. The bioactivity of the protein on a positive control was only verified by $10 \%$ of the studies (see Fig. 3; Additional file 7: Table S7).

Overall, $43 \%$ of the selected studies fulfilled five of the seven quality criteria. Twenty-seven percent fulfilled six of the criteria and none of them had the quality standards from all seven categories. Seventeen percent had the quality standards of four of the criteria and one study met three criteria. Two studies presented the quality standard for two and one study for a single criterion (see Fig. 4).

\section{Data extraction and narrative synthesis}

After identifying and describing the 32 studies we extracted the individual data. We regarded each pest population with each differently tested end point as a single data set. Over all we assembled and evaluated 1109 outcomes. 

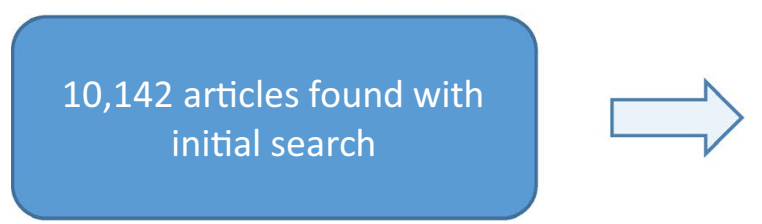

2,199 duplicates were removed
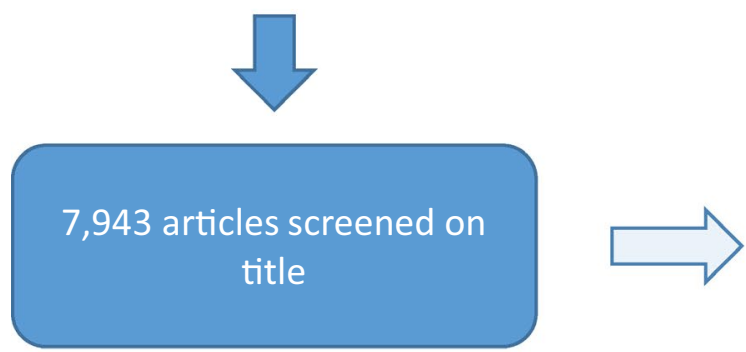

6,348 articles excluded during screening on title
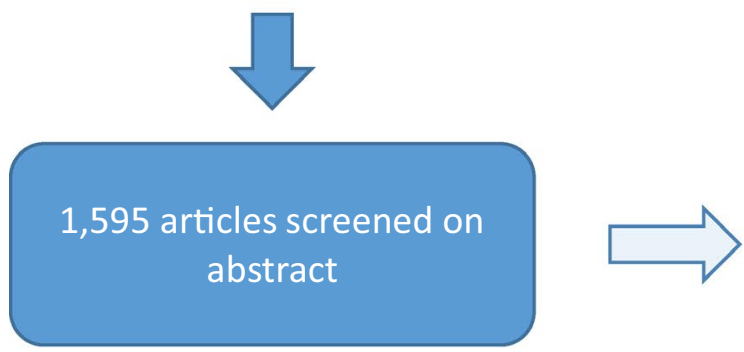

1,385 articles excluded during screening on abstract

212 articles plus 4 articles of grey literature screened on

\section{full text}

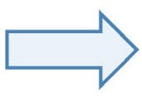

127 articles and 1 grey literature excluded during screening on full text

\section{0 articles plus 3 articles of grey literature identified as relevant}

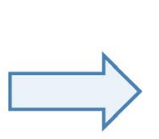

3 grey literature articles excluded as data were already in screened papers

\section{0 articles with}

\section{9 extracted data sets}

Fig. 1 Screening process showing the development of the selection procedure in blue at the left column and the discarded publications in grey at the right column. The final outcome is given in dark blue 

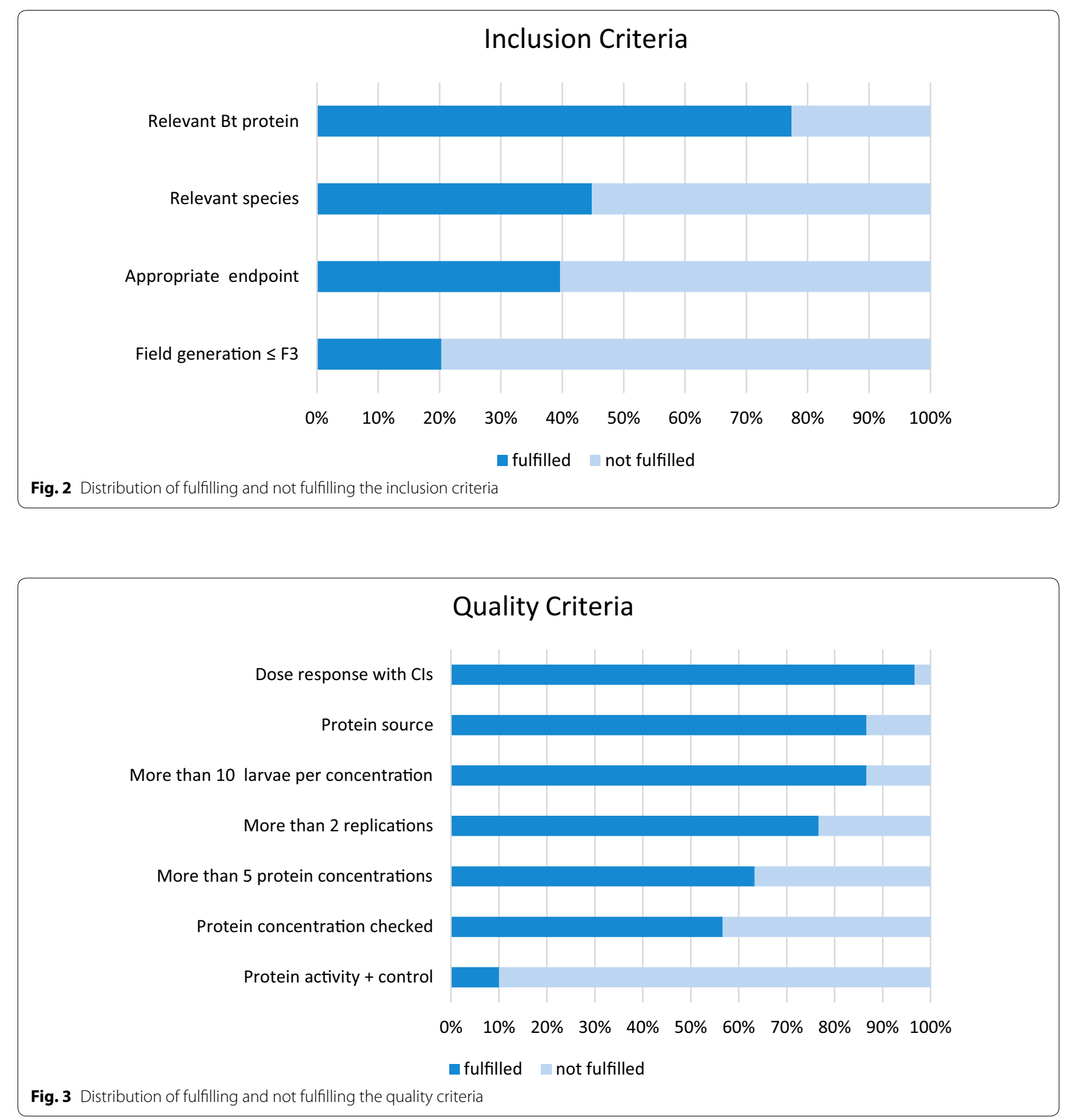

The selected studies revealed information about the economically relevant species in Europe, Ostrinia nubilalis, Sesamia nonagrioides, (Lepidoptera) and Diabrotica virgifera virgifera (Coleoptera). There were 377 data points (34\% of the data set) for O. nubilalis the most common pest in maize in Europe. In contrast, there were 28 data points for $S$. nonagrioides corresponding to $3 \%$ of the total and 12 data points for $D$. virgifera virgifera, which were $1 \%$ of the total extracted data (see Fig. 5). 692 data points (62\% of the results) were found for Helicoverpa armigera a regionally relevant species. Of the remaining species species Agrotis segetum and Autographa gamma had one data set, Mamestra brassicae two, and Agrotis ipsilon three data sets in the studies that were screened by full text, but these studies did not meet all the inclusion criteria as they used populations 

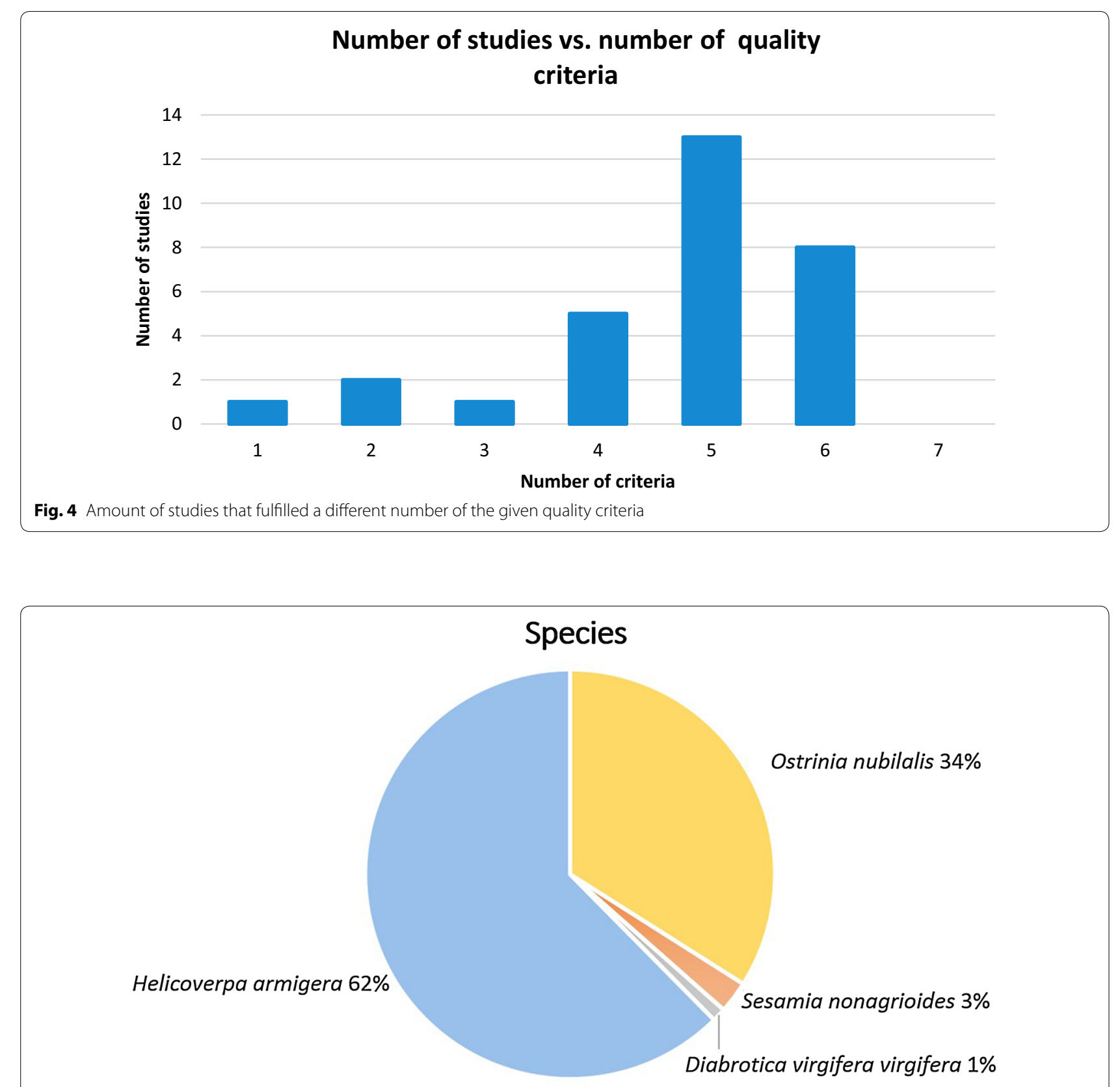

Fig. 5 Distribution of the studied species

that were reared in the laboratory for more than three generations. In addition some did not use lepidopteran or/and coleopteran specific $B t$ proteins expressed in $B t$ maize for their tests. As a result, we excluded them from further analysis, but nevertheless included them in the supplementary material. For the species Mythimna unipuncta, Acronicta rumicis, Sesamia cretica, and Xylena vetusta that were also identified as economically relevant or regional economic relevant maize pests in Europe [11], no study was included in our selection.

A high number of studies was performed in Asia, especially in India with $32 \%$ and China with $17 \%$ of the targeted populations (see Fig. 6). Seven percent of the data were collected in Europe. Most of these studies were conducted in Spain representing 3\% of all data points and $46 \%$ of the tested populations on this continent. 


\section{Distribution over Countries}

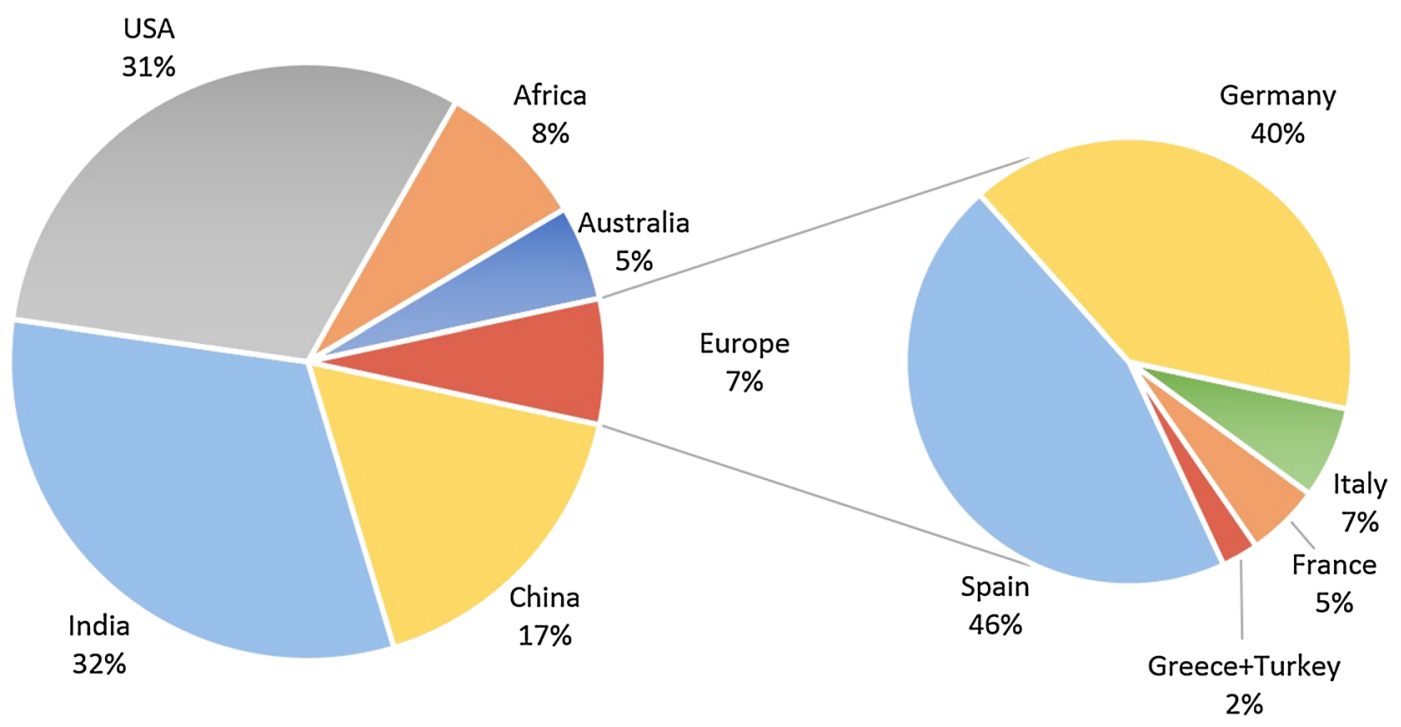

Fig. 6 Origin of the study populations over the world and over Europe in detail

Six $B t$ proteins were defined as relevant for the target species, because they are specific for Lepidoptera or/and Coleoptera and are expressed in Bt maize. The most commonly tested protein was Cry $1 \mathrm{Ac}$ for $45 \%$ of the populations, which is lepidopteran specific and widely used in GM cotton. Cry1F is the second most tested protein for $30 \%$ of the populations. This protein is regularly used in GM maize and GM cotton. The protein Cry1Ab, which is most commonly used in GM maize in Europe, was tested on $7 \%$ of the populations. The coleopteran specific protein Cry3Bb1 tested for D. virgifera virgifera is only used in maize due to the host specificity of the beetle, and was tested on 12 populations (see Fig. 7).

In the tests three different exposure methods were used. In $53 \%$ of the experiments the specific amounts of $B t$ protein were incorporated in the insect diet. In $46 \%$ of the tests $B t$ protein was applied to the surface of the insect diet. In $1 \%$ of the studies leaves were dipped in a $B t$ protein solution before feeding.

\section{Baseline susceptibility}

Values for the baseline susceptibility of the selected species $B t$ protein combinations were collected from the data sets. The endpoints $\mathrm{EC}_{50}$ and $\mathrm{LC}_{50}$ were examined. The endpoints $\mathrm{MIC}_{50}$ and $\mathrm{IC}_{50}$ (inhibitory concentration for $50 \%$ of the test organisms) were included in the results of $\mathrm{EC}_{50}$, as they also describe an effective concentration.

For O. nubilalis the proteins Cry1Ab, Cry1Ac, and Cry1F were analysed. Cry1Ac resulted in a more sensitive

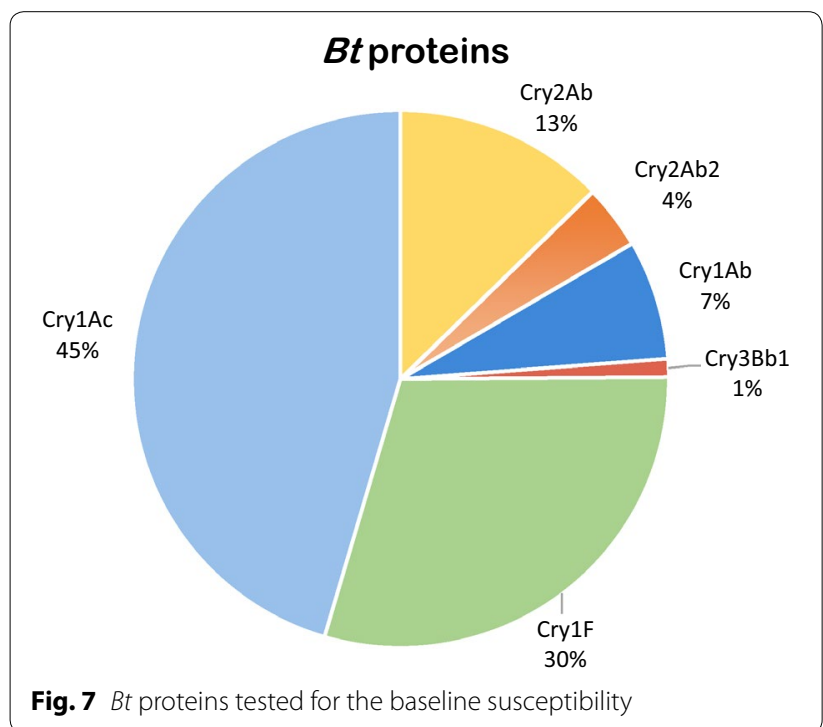

reaction than for the others regardless of determining $\mathrm{EC}_{50}$ or $\mathrm{LC}_{50}$ (see Table 1). As expected, the concentrations shown for the $\mathrm{EC}_{50}$ for each protein were lower than for the $\mathrm{LC}_{50}$. The results were extracted from seven studies after abstract screening, while 24 studies dealing with $O$. nubilalis were excluded.

Sesamia nonagrioides studies were examined for $\mathrm{LC}_{50}$ with Cry1 Ab and Cry1F (see Table 2). Two of five studies found and screened on full text fulfilled the four inclusion criteria and were considered for further analysis. 
Table 1 Baseline susceptibility of Ostrinia nubilalis

\begin{tabular}{llll}
\hline Ostrinia nubilalis & No. populations & Min & Max \\
\hline EC $_{50}$ diet surface $\left(\mathrm{ng} / \mathrm{cm}^{2}\right)$ & & & \\
Cry1AC & 10 & 0.052 & 0.13 \\
Cry1F & 143 & 0.3 & 2.65 \\
$\mathrm{LC}_{50}$ diet surface $\left(\mathrm{ng} / \mathrm{cm}^{2}\right)$ & & & \\
Cry1Ab & 28 & 3 & 109 \\
Cry1AC & 11 & 0.2 & 0.78 \\
Cry1F & 177 & 1.04 & 13.8 \\
$\mathrm{LC}_{50}$ incorporation $(\mu \mathrm{g} / \mathrm{l})$ & & & \\
Cry1Ab & 8 & 28 & 2120 \\
\hline
\end{tabular}

Table 2 Baseline susceptibility of Sesamia nonagrioides

\begin{tabular}{lccc}
\hline Sesamia nonagrioides & No. populations & Min & Max \\
\hline $\mathrm{LC}_{50}$ diet surface $\left(\mathrm{ng} / \mathrm{cm}^{2}\right)$ & & & \\
Cry1 $\mathrm{Ab}$ & 19 & 3 & 70 \\
Cry1F & 9 & 10 & 29.6 \\
\hline
\end{tabular}

Helicoverpa armigera was the species with most data points and also the most variable data (see Table 3). Four different $B t$ proteins were tested and three different test methods, determining for two methods both $\mathrm{LC}_{50}$ and $\mathrm{EC}_{50}$. $H$. armigera demonstrated a higher sensitivity to Cry1Ac than for the other Bt proteins. In total, we included 21 studies for this survey, while 36 screened $H$. armigera sets were excluded.

Six datasets studied the sensitivity of $D$. virgifera virgifera. However, only one matched the four inclusion criteria testing $\mathrm{EC}_{50}$ with the coleopteran specific protein Cry3Bb1 (see Table 4).

\section{Discussion}

The broad objective of our systematic review was to gather relevant information for the successful management of pest resistance for the cultivation of $B t$ maize in Europe. Therefore, we collected data on the baseline susceptibility of different lepidopteran/coleopteran maize pests. Besides the use of $B t$ proteins in $B t$ maize insecticidal $B t$ proteins are used also in sprays like Dipel ${ }^{\circledR}$. These are applied against different insect pests worldwide [14] in both organic and conventional agriculture [15]. Considering our inclusion criteria, we searched for studies of the $B t$ proteins that are expressed in commercial $B t$ maize varieties and that are toxic to European target organisms. Therefore, we excluded studies that used $B t$ formulations or the untruncated version of the $B t$ proteins for testing (23\% of the studies).
Table 3 Baseline susceptibility of Helicoverpa armigera

\begin{tabular}{|c|c|c|c|}
\hline Helicoverpa armigera & No. populations & Min & Max \\
\hline \multicolumn{4}{|l|}{$\mathrm{EC}_{50}$ incorporation $(\mu \mathrm{g} / \mathrm{l})$} \\
\hline Cry1Ab & 14 & 2 & 1140 \\
\hline Cry1Ac & 177 & 0.3 & 3000 \\
\hline Cry2Ab & 47 & 100 & 3400 \\
\hline Cry2Ab2 & 29 & 10 & 8720 \\
\hline \multicolumn{4}{|c|}{$\mathrm{EC}_{50}$ diet surface $\left(\mathrm{ng} / \mathrm{cm}^{2}\right)$} \\
\hline Cry1Ab & 8 & 390 & 1300 \\
\hline Cry2Ab & 13 & 140 & 600 \\
\hline \multicolumn{4}{|l|}{$\mathrm{LC}_{50}$ incorporation $(\mu \mathrm{g} / \mathrm{l})$} \\
\hline Cry1Ab & 11 & 54 & 1990 \\
\hline Cry1Ac & 236 & 8.5 & 16,710 \\
\hline Cry2Ab & 48 & 2140 & 34,260 \\
\hline Cry2Ab2 & 14 & 5120 & 50,710 \\
\hline \multicolumn{4}{|c|}{$\mathrm{LC}_{50}$ diet surface $\left(\mathrm{ng} / \mathrm{cm}^{2}\right)$} \\
\hline Cry1Ac & 49 & 0.031 & 207 \\
\hline Cry2Ab & 33 & 22 & 420.2 \\
\hline \multicolumn{4}{|l|}{$\mathrm{LC}_{50}$ leaf surface $(\mu \mathrm{g} / \mathrm{l})$} \\
\hline Cry1Ac & 13 & 52 & 1095 \\
\hline
\end{tabular}

Table 4 Baseline susceptibility of Diabrotica virgifera virgifera

\begin{tabular}{llll}
\hline Diabrotica virgifera virgifera & No. populations & Min & Max \\
\hline $\mathrm{EC}_{50}$ diet surface Cry3Bb1 $\left(\mathrm{ng} / \mathrm{cm}^{2}\right)$ & 12 & 0.97 & 4.14 \\
\hline
\end{tabular}

Many studies examined the effect of $B t$ proteins on a range of potential pests. However, studies targeting relevant European species were rarer as most studies in our survey were conducted outside Europe. In Europe only Spain cultivates maize at a significant level [16] and this limited cultivation is likely to influence the level of research. Most of the studies found in our survey were conducted in India and China. One explanation is the high amount of $B t$ cotton grown in this area expressing $B t$ proteins to control $H$. armigera as the main cotton pest, and thus the interest to protect this technology.

We identified appropriate endpoints-our third inclusion criterion-, in about $40 \%$ of the studies. The aim of the different screened studies varied. Many toxicity studies tested for survival [17-19] or mortality only (e.g. [2022]). Other studies focussed on a selective breeding and did not contain these measurement endpoints [23-25].

Only $20 \%$ of the studies tested field populations that were reared in the laboratory for not more than three generations, our fourth criterion. Again, the intention of the studies varied. Toxicity treatments were often used 
to select resistant insects. As a result, laboratory strains were used for several generations [26].

In summary, we identified 30 relevant articles matching our inclusion criteria. In total we found 1109 data sets of four tested pest species. We extracted all data and sorted it first for the tested species and second for the different $B t$ proteins tested. We considered a quality assessment of the data for the further analysis not necessary, as we could not perform a meta-analysis of the extracted data because of their heterogeneity.

\section{Heterogeneity}

The heterogeneity of the studies and consequently of the resulting data is high due to several factors. Bt proteins were obtained from different sources and when obtained from the same source different protein batches may have different measured sensitivity of the targeted pest [27]. The tested Bt proteins may have had variable purity and/ or storage stability [28]. As no common protocol was used, deviations in the applied methods were likely to give different results. Finally, the range of susceptibility data of different populations of the target pests, as shown with Helicoverpa armigera, are an additional heterogeneity factor. The large differences between the minimal and the maximal $\mathrm{LC}_{50}$ values in susceptibility tests in China $(0.09-9.073 \mathrm{mg} / \mathrm{ml})$ indicated resistance of the pest insects. However, resistance was not explicitly described and the high variation in susceptibility was due to population variability [29].

For our analysis, we divided the experimental design of the studies into three main types. The surface method, where a protein solution was applied only on the surface of an artificial diet, the incorporation method, where the $B t$ protein was mixed completely with an artificial diet and the leaf surface application. The experimental types differed also in the number of replicates, number of concentrations, size of the controls and/or the measured endpoints.

In consequence, the extracted data on the susceptibility tests were difficult to compare so that the performance of a meta-analysis was not considered valid.

\section{Strength and limitations of the study}

Our systematic review of baseline susceptibilities of coleopteran/lepidopteran pests gives a comprehensive and unbiased overview of conducted and published studies focusing on insect pest species with potential economic impact for maize cultivation in Europe. It shows the range of different test systems and gives an impression of susceptibility spectrums of the tested species. Our literature search was restricted to papers written in English only. Some data resources such as GM maize applications for the European market and monitoring reports, which both contain susceptibility data of European maize pests, are owned by the applicants and could not be used because of data confidentiality and copyright issues.

The available data is unequally distributed between the different species. Most data were related to Helicoverpa armigera and Cry1Ac, and had limited relevance to $B t$ maize cultivation in Europe. $H$. armigera feeds on a range of cultivated plants, and in Europe it is a minor pest of maize. H. armigera is an economic pest of cotton in India and China and therefore $B t$ cotton cultivation practices include resistance management of this pest in these countries. Maize GM events expressing Cry1 Ac could be of interest for cultivation in Europe in the future.

No explicit resistance of Diabrotica virgifera virgifera (Western Corn Root Worm, WCR) was described in the single included study. Nevertheless, infield resistance of WCR against Cry3Bb1-expressing $B t$ maize is known from Iowa, USA [30]. Discussing the survival studies with Western Corn Rootworms, the authors suspected ignorance of the high dose principle as a reason for the fast evolution of resistance to Cry3Bb1-expressing $B t$ maize of WCR [31].

Our systematic review gives a comprehensive overview of available data on susceptibility of coleopteran/lepidopteran pests to $B t$ proteins. The review shows some lack of evidence, but illustrates in particular the requirement of a common test protocol to ensure the comparability of data.

\section{Conclusion \\ Implication for policy/management}

The cultivation of $B t$ crops, as with any other plant protection measure, is likely to result in resistance evolution in the target pests. This underlines the importance of resistance management including the collection of data on baseline susceptibility. In addition, monitoring changes in susceptibility during the cultivation is another indispensable component of the high dose/refuge strategy. Our findings suggest that the evidence base needs strengthening and industry, policy makers, and research should combine knowledge to protect the benefits of this technology and a first step would be to make data from monitoring reports for a scientific analysis available.

\section{Implication for research}

Our systematic review illustrates the heterogeneity of the different studies and the resulting data and indicates the necessity of standard protocols for testing susceptibility of insect pests, which provide comparable data [32]. Furthermore, "bridging studies" to calculate a factor for the ratio of microbial protein to plant protein would be helpful in order to standardize exposure assessments. A ring trial to test the comparability of the involved laboratories and to verify the methodology is desirable. 


\section{Additional files}

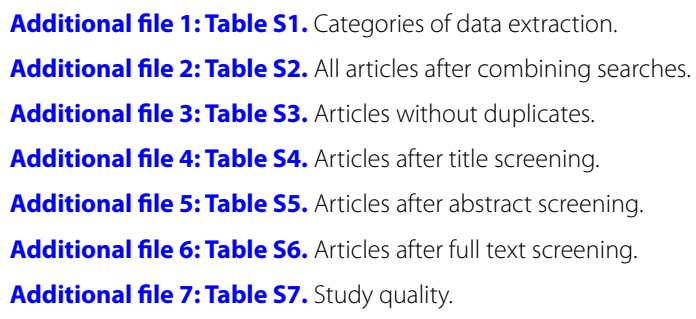

\section{Abbreviations}

Bt: Bacillus thuringiensis; GM: genetically modified; EU: European Union; EFSA: European Food Safety Authority; SR: systematic review.

\section{Authors' contributions}

All authors read and approved the final manuscript.

\section{Acknowledgements}

We are grateful to the EU for funding our project and would like to thank all project partners of GRACE for the productive collaboration.

\section{Competing interests}

The authors declare that they have no competing interests.

\section{Availability of data and materials}

The datasets supporting the conclusions of this article are included within the article and its additional files.

\section{Funding}

This review was funded by the EU in the Seventh Framework Programme (EU FP7-KBBE/311957): KBBE.2012.3.5-04-Verification of GMO risk assessment elements and review and communication of evidence collected on the biosafety of GMO. The Authors are scientific officers at the Federal Office of Consumer Protection and Food Safety (BVL) in Berlin, Germany.

Received: 28 April 2016 Accepted: 16 November 2016

Published online: 12 December 2016

\section{References}

1. Andow DA. The risk of resistance evolution in insects to transgenic insecticidal crops. Coll Biosafety Rev. 2008;4:142-99.

2. Roush RT. Managing pests and their resistance to Bacillus thuringiensis: can transgenics be better than sprays? Biocontrol Sci Technol. 1994:4:501-16.

3. Tabashnik BE. Delaying insect adaption to transgenic plants: seed mixtures and refugia reconsidered. Proc Roy Soc B Biol Sci. 1994:255:7-12.

4. Hokkanen $\mathrm{HM}$, Wearing $\mathrm{CH}$. The safe deployment of Bacillus thuringiensis genes in crop plants: conclusions and recommendations of OECD workshop on ecological implications of transgenic crops containing Bt toxin genes. Biocontrol Sci Technol. 1994:4:399-404.

5. Tabashnik BE, Gould F. Delaying Corn Rootworm Resistance to Bt Corn. J Econ Entomol. 2012;105:767-76.

6. EFSA. Scientific opinion on the annual post-market environmental monitoring (PMEM) report from Monsanto Europe S.A. on the cultivation of genetically modified maize MON 810 in 2013. EFSA J. 2015;13(3):4039.

7. Devos Y, Meihls LN, Kiss J, Hibbard BE. Resistance evolution to the first generation of genetically modified Diabrotica-active Bt-maize events by western corn rootworm: management and monitoring considerations. Transgenic Res. 2013;22:269-99.

8. Riedel J, Romeis J, Meissle M. Update and expansion of the database of bio-ecological information on non-target arthropod species established to support the environmental risk assessment of genetically modified crops in the EU. EFSA J. 2016;956:109.

9. Gasper C. The European corn borer (Ostrinia nubilalis, Hbn.), its susceptibility to the Bt-toxin Cry1F, its pheromone races and its gene flow in Europe in view of an Insect Resistance Management. Dissertation RWTH Aachen University 2010. http://publications.rwth-aachen.de/ record/229060/files/3341.pdf.

10. Meise T. Monitoring der Resistenzentwicklung des Maiszünsler (Ostrinia nubilalis, Hübner) gegenüber Bt-Mais. Dissertation Georg-AugustUniversität Göttingen 2004. https://ediss.uni-goettingen.de/bitstream/ handle/11858/00-1735-0000-0006-ADEE-7/meise.pdf? sequence $=1$.

11. Saeglitz C. Untersuchungen der genetischen Diversität von MaiszünslerPopulationen (Ostrinia nubilalis, Hbn.) und ihrer Suszeptibilität gegenüber dem Bacillus thuringiensis (Bt)-Toxin als Grundlage für ein Resistenzmanagement in Bt-Maiskulturen. Dissertation RWTH, Aachen University. 2004. http://publications.rwth-aachen.de/record/61044/files/Saeglitz_Christiane.pdf.

12. Gathmann A, Priesnitz KU. How susceptible are different lepidopteran/ coleopteran maize pests to Bt-proteins: a systematic review protocol. Environ Evidence. 2014;3:12

13. Reference manager professional version 12, @ Thomson Reuters. 2014.

14. Ferré J, Van Rie J. Biochemistry and genetics of insect resistance to Bacillus thuringiensis. Annu Rev Entomol. 2002;47:501-33.

15. Tabashnik BE. Evolution of Resistance to Bacillus thuringiensis. Annu Rev Entomol. 1994;39:47-79.

16. James C. Global status of commercialized biotech/GM crops. ISAAA 2014 brief no 49. Ithaca: ISAAA; 2014.

17. Mahon R, Olsen K. Limited survival of a Cry2Ab-resistant strain of Helicoverpa armigera (Lepidoptera: Noctuidae) on Bollgard II. J Econ Entomol. 2009;102(2):708-16.

18. Pereira EJ, Lang BA, Storer NP, Siegfried BD. Selection for Cry1F resistance in the European corn borer and cross-resistance to other Cry toxins. Entomol Exp Appl. 2008;126:115-21.

19. Petzold-Maxwell JL, Siegfried BD, Hellmich RL, Abel CA, Coates BS, Spencer TA, Gassmann AJ. Effect of maize lines on larval fitness costs of Cry1F resistance in the european corn borer (Lepidoptera: Crambidae). J Econ Entomol. 2014;107(2):764-72.

20. Guan X, Liu X, Lu Z, Zhao Z, Zhang Q, Xia J. Influence of tannic acid and Cry1Ac toxin of Bacillus thuringiensis on larval survival, growth, and development of Helicoverpa armigera. Entomol Exp Appl. 2009;132:50-8

21. Hallad A, Udikeri SS, Patil SB, Khadi BM, Biradar DP, Goud KB, Bhat ARS. Characterization of resistance of different cry toxins to early and late instar Helicoverpa armigera (Hub.) and Spodoptera litura (Fab.). Karnataka. J Agric Sci. 2011;24(3):300-2.

22. Kannan M, Uthamasamy S. Baseline susceptibility of the cotton bollworm Helicoverpa armigera (Hübner) (Lepidoptera: Noctuidae) to transgenic Bt cotton (RCH 2) in South India. Biopestic Int. 2007;3(1):71-8.

23. Singh S, Gill HK, Sharma RK, Gupta VK, Dilawari VK. Susceptibility and fitness cost of cotton bollworm, Helicoverpa armigera associated with cry 1Ac toxin of Bt cotton. Indian J Plant Prot. 2009;37(1/2):29-34

24. Lu MG, Rui CH, Zhao JZ, Jian GL, Fan XL, Gao XW. Selection and heritability of resistance to Bacillus thuringiensis subsp kurstaki and transgenic cotton in Helicoverpa armigera (Lepidoptera: Noctuidae). Pest Manag Sci. 2004;60:887-93.

25. Chaufaux J, Seguin M, Swanson JJ, Bourguet D, Siegfried BD. Chronic exposure of the European corn borer (Lepidoptera: Crambidae) to CrylAb Bacillus thuringiensis toxin. J Econ Entomol. 2001;94(6):1564-70.

26. Bird LJ, Akhurst RJ. Relative fitness of CrylA-resistant and -susceptible Helicoverpa armigera (Lepidoptera: Noctuidae) on conventional and transgenic cotton. J Econ Entomol. 2004;97(5):1699-709.

27. Saeglitz C, Gathmann A, Priesnitz KU, Schuphan I, Bartsch D. Monitoring the Cry1 Ab susceptibility of European Corn Borer (Ostrinia nubilalis $\mathrm{Hbn}$.) in Germany. J Econ Entomol. 2006;99:1768-73.

28. Nguyen HT, Jehle JA. Stability of Cry1Ab protein during long-term storage for standardization of insect bioassays. Environ Biosafety Res. 2009;8:113-9.

29. Wu K, Guo Y, Lv N. Geographic variation in susceptibility of Helicoverpa armigera (Lepidoptera: Noctuidae) to Bacillus thuringiensis insecticidal protein in China. J Econ Entomol. 1999;92:273-8. 
30. Gassmann AJ, Petzold-Maxwell JL, Keweshan RS, Dunbar MW. Western corn rootworm and $B t$ maize —Challenges of pest resistance in the field. GM Crops Food. 2012;3:235-44.

31. Gassmann AJ, Petzold-Maxwell JL, Keweshan RS, Dunbar MW. Fieldevolved resistance to Bt maize by western corn rootworm. PLoS ONE. 2011;6(7):e22629. doi:10.1371/journal.pone.0022629.
32. Siegfried BD, Spencer T, Crespo AL, Storer NP, Head GP, Owens ED, Guyer $D$. Ten years of Bt resistance monitoring in the European corn borer: what we know, what we don't know, and what we can do better. Am Entomol. 2007:53(4):208-14.
Submit your next manuscript to BioMed Central and we will help you at every step:

- We accept pre-submission inquiries

- Our selector tool helps you to find the most relevant journal

- We provide round the clock customer support

- Convenient online submission

- Thorough peer review

- Inclusion in PubMed and all major indexing services

- Maximum visibility for your research

Submit your manuscript at www.biomedcentral.com/submit
() Biomed Central 